\title{
Appraising clinical guidelines: towards a "Which" guide for purchasers
}

All health care services are attempting to control escalating costs in the face of increasing patient needs, expectations, and healthcare interventions. In the United Kingdom the government has responded in two ways: by introducing a competitive health market to provide incentives for efficiency and an emphasis on providing only those services that have been shown to be clinically effective. The latter approach has concentrated on changing professional behaviour through the introduction of a national audit programme ${ }^{1}$ and a research and development strategy. ${ }^{2}$

Clinical guidelines are proposed as the logical link between these initiatives, with purchasers being encouraged to include evidence based guidelines in their contracts as a method of increasing clinical effectiveness. ${ }^{3}$ Simply put, the research and development initiative will define appropriate practice, which will be translated into statements of good care (guidelines), and clinical audit will monitor adherence to the guidelines. ${ }^{45}$ The potential benefits are enormous: an increase in appropriate practice and hence reduced morbidity and mortality; improved efficiency by controlling professional excess; and cost containment by targeting finite resources on effective interventions.

\section{Hurdles to implementation}

However, like all policies attempting to alter professional practice, implementation is proving difficult. The medical profession values clinical freedom and has been suspicious of guidelines. If clinical practice is now to be explicitly linked by guidelines to managerial processes, reassurance is needed that those guidelines will acheive their intended outcome. But how can the quality of guidelines be assessed? The increasing number of local $^{6}$ and national ${ }^{7}$ guidelines available means that purchasers and providers may benefit from a "Which" style report with guidelines appraised against predefined desirable criteria. Is it possible to develop such guidance?

\section{Assessing the validity of guidelines}

The essential prerequisite for improved quality of care is that a guideline is valid. In this context validity means that adherence to the guideline will increase the probability of bringing about the expected health outcome at the expected cost. Guidelines are likely to be more valid if they are based on the results of systematic reviews of the evidence, if they have been developed by national multidisciplinary groups representing the interests of key stakeholders, and if the recommendations are explicitly linked to evidence. ${ }^{8}$

Appraising the validity of guidelines depends on the availability of the documentation on their development. A recent pilot study appraised several guidelines published in the United Kingdom against a modified version of the criteria of United States Institute of Medicine (F Cluzeau, et al, unpublished report). ${ }^{9}$ These criteria were based on eight desirable attributes of clinical practice guidelines and addressed whether developers overcame potential biases during development of the guidelines. The criteria emphasised the importance of identifying, rating, and synthesising evidence; quantifying the potential costs, risks, and benefits of management options; and using appropriate consensus techniques. After collecting available background information for each guideline we asked a multidisciplinary group of reviewers to assess its performance against the proposed criteria. The study disclosed that most guidelines had insufficient documentation to assess the process of their development. Without such information reviewers often felt unable to make a judgement, or if they did, they recognised that this was based on their personal knowledge of the guidelines. Even when the information was sufficient, agreement between reviewers remained poor.

These preliminary findings raise some important issues about appraising guidelines in the United Kingdom. Firstly, how can the scientific rigour of the guidelines be objectively evaluated without adequate documentation? The lack of transparency about how current guidelines have been developed presents a major hurdle for their appraisal. In future, those developing guidelines should publish sufficient information about the development process to allow potential users to assess their likely validity, ${ }^{10}$ possibly as a structured abstract. ${ }^{11}$ Secondly, who should undertake the assessment? Without an organisational framework the appraisal of guidelines by individual purchasers and providers is likely to lead to duplication of efforts and diseconomies of small scale. These problems could be largely contained through national coordination by professional bodies, following the examples of the Scottish intercollegiate Guidelines Network (J Petrie, personal communication) and the Dutch College of General Practitioners, ${ }^{12}$ or as part of the research and development initiative. Potentially useful guidelines identified through these processes could be recommended to purchasers and providers, who could concentrate on how they could be adopted locally, ${ }^{13}$ including auditing their impact.

\section{Ensuring quality of guidelines}

Including guidelines in contracts is complex and experimental. The latest letter from the NHS Management Executive on clinical effectiveness reflects increasing understanding of these issues. ${ }^{14}$ If guidelines are to be used by purchasers and providers they must be developed rigorously and must identify outcomes for monitoring purposes. Evidence so far suggests that current guidelines in the United Kingdom are deficient in these respects. The challenge for those producing guidelines is to ensure that the development process is rigorous and amenable to scrutiny. The challenge for those involved in appraising guidelines is to develop sensitive and reliable 
criteria that will inform purchasers and providers about the strengths and weaknesses of published guidelines. Until then, the introduction of a "Which" guide to guidelines is premature.

The Health Services Research Unit is funded by the Chicf Scientist Office of the Scottish Office Home and Health Department: however the opinion expressed are those of the authors and not the SOHHD.

FRANCOISE CLUZEAL

Research Fellow

PETER IITTTLEJOHNS

Director

Health Care Evaluation Unit,

Department of Public Health Sciences,

St George's Hospital Medical School,

London SW17 ORE

\section{JEREMY M GRIMSHAW}

Programme Dirctor

Health Services Research Unit,

University of Aberdeen,

Foresterhill, Aberdeen AB9 $2 Z D$
Secretaries of State for Health, Wales, Northern Ireland, and Scotland Working for patiolts. London: HMSO), 1989. (Cmnd 555 .)

Peckham M. Research for health. London: Department of Health, 1993.

Sheldon TA, Borowitz M. (Changing the measure of quality in the NHS from purchasing activity to purchasing protocols. (Itcality in Health (Can 10) $3: 2: 1.4950$.

$t$ Haines A fones R. Implementing findings of research. B.117 1994 308: 1488.92.

From research to practice |liditoriall Lancid 1091:344:417 \&

6 Littlciohns P. Sharda A cuideline and protecols for sharing of health care between hespitals and general practitioners in South West Thames. Medical Audit Nices 1994:4(0):1-2.

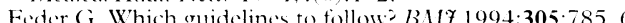

Crimshaw JM, Russell IT. Achicving health gain through clinical guidelines. I. I)eveloping scientifically valid guidelines. (Guality in Hidth Ciali 199) 3:2:243

Field MJ, Lohr KN, eds. (imidilines for dimical practica: from derelopmen 16) usc. Washington, DC: National Academy Press, 1902

10 (Grimshaw JM. Guidelines. BMY 1994:307:1531

11 Harward RSA, Wilson .MI), Tunis SR, Buss EB, Rubin HR. Harnes RB. Hore informatice abstracts of articles on clinical practice guidelines. Alun Intin Med 1993;118:731-i

12 Grol R. Development of guidelines for general practice care. $B r .7$ G Pract 1993:43:146 51

13 Havward I. Purchasing clinically effective care. National directives cannor be fulfilled without local collaboration. BAIf 1994;309:823 t.

14 NHS Management Executive. Improsing the cffectiveness of the NHS ecds: NHSME, 1994. (EI.(94)7.4 